In research into clinical, pathological, or social problems of ageing the psychogeriatric unit would be in a position to provide almost unlimited opportunities. Since the medicine of the future will be increasingly the medicine of old age, this nettle should be firmly grasped now.

\section{REFERENCES}

Bergmann, K., Foster, E., and Kay, D. W. K. (1965). Paper read at London Symposium of World Psychiatric Association, September. To be published.

Enoch, M. D. (1963). Lancet, 1, 1160.

Fish, F., and Williamson, J. (1964). Geront. clin. (Basel), 6, 71

Godber, G. (1962). Care of the Elderly. The Elderly Individual in Modern Society. National Old People's Welfare Council, London. Hall, T. (1965). Lancet, 1, 1325.

Joint Commission on Mental Illness and Health (1961). Action for Mental Health. Final report. Basic Books, New York.
Kay, D. W. K., Beamish, P., and Roth, M. (1962). The Sociological Review, Monogr. No. 5.

Tid (1964). Brit. F. Psychiat., 110, 146.

Kidd, C. B. (1962). Brit. med. F., 2, 1491.

McMullan, J. J. (1963). Postgrad. med. 7., 39, 382

Ministry of Health (1962).A Hospital Plan for England and Wales.

H.M.S.O., London. (1965). Care of the Elderly in Hospitals and Residential Homes. H.M. (65) 77. (Limited distribution to Hospital Boards and Local Authorities.)

Nisbet, N. H. (1962). Lancet, 1, 903.

Robinson, R. A., and Isaacs, B. (1963). Report to Scottish Western Regional Hospital Board (unpublished)

Royal College of Physicians of Edinburgh (1963). The Care of the Elderly in Scotland. R.C.P., Edinburgh.

Rudd, T. N. (1963). Postgrad. med. F., 39, 394.

- Townsend, P. (1957). The Family Life of Old People. Routledge, London.

- (1962). The Last Refuge. Routledge, London.

W.H.O. (1959). Wld Hlth Org. Techn. Rep. Ser., No. 171

Whitehead, J. A. (1965). Lancet, 2, 583 .

Wollner, L. (1964). Geront. clin. (Basel), 6, 65

Woodside, M. (1965). Ibid., 7, 286.

\title{
Assessment of Respiratory Function in the Asthmatic Child
}

\author{
R. S. JONES,* M.D., M.R.C.P., D.C.H.
}

Brit. med. F., 1966, 2, 972-975

Clinical reports concerning the action of drugs, the influence of environment, infection, and psychological and allergic factors have lacked a satisfactory definition of "asthma" in physiological terms and means of measuring objectively changes in ventilatory function. Progress was made with the application of tests of respiratory function, but the position is still not entirely satisfactory. Tests of ventilatory function, such as the forced expiratory volume in one second (F.E.V., ), applied in the conventional manner, do not distinguish between asthma and other respiratory disorders, because they do not pinpoint the specific abnormality of function in the asthmatic-namely, a labile type of bronchoconstriction. Thus the F.E.V., may be normal at certain times in some subjects with severe asthma. What is required of ventilatory tests in asthma is greater specificity for the disease and a classification of the physiological abnormalities based upon such tests which correlates well with the main clinical features. An appropriate technique for examining ventilatory function and a classification of asthma are here described, based upon the F.E.V..$_{1}$ test.

\section{Evidence of Bronchial Lability}

It has been shown that physical exercise in the form of running for five to eight minutes is followed in asthmatic subjects by bronchoconstriction as indicated by a fall in the F.E.V. below the pre-exercise resting value (Jones et al., 1962). In order to obtain maximum bronchodilatation in the asthmatic it is necessary to give isoprenaline in the form of an aerosol followed by one minute's exercise (Jones et al., 1963). By standardizing the use of exercise and drugs in the way defined by these authors it is possible to obtain an objective measure of the tendency of the bronchi to constrict and dilate in a given subject. If the fall and rise in litres below and above the resting value are added and expressed as a percentage of the predicted normal for that subject, the figure obtained can be used as an index of bronchial lability.

Lability index =

$$
\frac{\text { Fall of F.E.V.1 in litres }+ \text { Rise of F.E.V.1 in litres }}{\text { Predicted normal F.E.V.1 at rest }} \times 100
$$

In the normal subject,

Lability index =

Fall of F.E.V.1 in litres + Rise of F.E.V.1 in litres F.E.V.1 at rest

\section{Classification}

It will be shown that with few exceptions the lability index in normal children is less than $15 \%$. The lability in asthmatic subjects always exceeds $20 \%$, with the exception of a few in whom it lies between 15 and $20 \%$.

It will be shown that when isoprenaline and exercise are used to produce maximum bronchodilatation the majority of asthmatic children have values for F.E.V., which lie within the predicted normal range. These children may be subdivided into two groups (groups 1 and 2), according to whether the lability is low or high. The remainder, with resting values below normal after maximum bronchodilatation, form a separate group (group 3).

Group 1. F.E.V.1 normal at rest, after maximum bronchodilatation. Lability index less than $30 \%$.

Group 2. F.E.V.1 normal at rest, after maximum bronchodilatation. Lability index greater than $30 \%$.

Group 3. F.E.V.1 below normal at rest, after maximum bronchodilatation. Lability index variable.

In all groups the lability exceeds $20 \%$, with a few exceptions in group 1 which lie between 15 and $20 \%$.

\section{Methods}

Ventilatory capacity was measured by the F.E.V.1 test. A modified Gaensler spirometer ${ }^{1}$ was used which records the volume of gas expired in the first second of a forced expiration, excluding the first $100 \mathrm{ml}$. (Gaensler, 1951; McKerrow et al., 1960). The instrument was recalibrated daily by the method described by McKerrow et al. (1960). The F.E.V. ${ }_{1}$ and forced vital capacity (F.V.C.) were recorded and results expressed at B.T.P.S. (body temperature and prevailing pressure and saturation).

Details of the exercise tests have been described elsewhere (Jones et al., 1963). Exercise took the form of running. Bronchoconstriction was produced by exercise lasting up to eight minutes. With experience, the occurrence of bronchoconstriction during exercise could be recognized by the devel* Alder Hey Children's Hospital and the Department of Child Health,

${ }^{1}$ Made by Poulton and Sons, of Penarth, South Wales. 
opment of excessive breathlessness after three to five minutes, in which case it was terminated and the F.E.V., recorded minute by minute.

After the F.E.V..$_{1}$ had returned to the resting value, or on a subsequent visit, maximum bronchodilatation was produced by giving isoprenaline sulphate $1 \%$ as an aerosol (Burroughs Wellcome preparation), followed immediately by one minute's exercise. A Wright inhaler and face-mask with an air-flow rate of 8-9 litres per minute were used (Wright, 1958). The aerosol was inhaled for one minute and two subsequent half-minute periods during a total time of five minutes. All observations of F.E.V..$_{1}$ were made with the subject sitting.

Measurements of lung volume were made with a closedcircuit system containing helium, which was detected by a katharometer ${ }^{2}$ in the circuit (Gilson and Hugh-Jones, 1949).

Single-breath $\mathrm{N}_{2}$ washout tests were made with a nitrogen meter, ${ }^{3}$ with a response time of $<0.04$ second for $90 \%$ of a square wave change in $\mathrm{N}_{2}$ concentration, and results were expressed as percentage rise in nitrogen between 500 and 1,000 $\mathrm{ml}$. of expired gas. In a number of instances the expired volume was insufficient to provide a valid measurement and these results were discarded.

Seventy-four children were examined between the ages of 6 and 15 years. They were in-patients or out-patients attending for the treatment of asthma, or were referred by physicians for the assessment of respiratory function.

In addition a follow-up study on 16 children was performed over a period of approximately three years between 1962 and 1965. The technique for measuring the lability index was not in use when this study began, so that the only comparison available is the fall of F.E.V. below the resting value after exercise.

It must be stressed that subjects were examined only when free from an attack of asthma, so that the classification describes the subject's physiological state at such a time.

\section{Results}

The results in 18 normal boys are shown in Table $I$. All but two showed a small increase of F.E.V. ${ }_{1}$ in response to maximum bronchodilatation with isoprenaline and one minute's exercise, and half of them did not fall after eight minutes' exercise. The lability in all but two subjects was less than $15 \%$, and in the two exceptions it lay between 15 and $20 \%$.

\begin{tabular}{|c|c|c|c|c|}
\hline & \multirow[t]{3}{*}{ TABLE } & I. -18 & Normal S & Subjects \\
\hline & & & \multicolumn{2}{|c|}{$\%$ Resting Value } \\
\hline & & & Mean & Range \\
\hline $\begin{array}{l}\text { F.E.V.1 at rest } \\
\text { Lowest F.E.V. } \\
\text { Highest P.E.V.'. } \\
\text { Lability index }\end{array}$ & $\begin{array}{ll}. & . \\
\because & \because \\
. . & . .\end{array}$ & $\begin{array}{l}. \\
\because \\
\because\end{array}$ & $\begin{array}{l}100 \\
97 \\
106 \\
8\end{array}$ & $\begin{array}{r}88-100 \\
100-118 \\
0-18\end{array}$ \\
\hline
\end{tabular}

\begin{tabular}{|c|c|c|c|}
\hline & Group 1 (10) & Group 2 (53) & Group 3 (11) \\
\hline & $\% \mathrm{~N}^{*}$ & $\% \mathrm{~N}^{*}$ & $\% \mathbf{N}^{*}$ \\
\hline \multirow{2}{*}{ 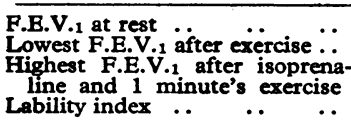 } & $\begin{array}{l}84(71-102) \\
70(61-81)\end{array}$ & $\begin{array}{l}80(31-115) \\
36(16-67)\end{array}$ & $\begin{array}{l}52(27-73) \\
32(17-47)\end{array}$ \\
\hline & $\begin{array}{l}94(85-107) \\
24(18-28)\end{array}$ & $\begin{array}{l}97(82-136) \\
61(34-86)\end{array}$ & $\begin{array}{l}69(39-79) \\
37(22-57)\end{array}$ \\
\hline
\end{tabular}

Table II shows the results in 74 children with asthma who were unselected, so that the number in each group, 10,53, and 11 , indicates the relative sizes of the groups in a population of asthmatic subjects. In group 1 the mean increase and decrease above and below the resting value was approximately

- Made by Godart-Miinhardt, N.V.

- Med. Science Electronics, U.S.A. equal, $10 \%$ and $14 \%$, giving a mean lability index of $24 \%$ for the group. Two subjects in group 1 had a lability index between 15 and $20 \%$. This range must be regarded as one within which normal subjects and those with mild asthma may fall.

Group 2 is the largest, and although the F.E.V., at rest is often below normal it tends to be high, so that the mean fall of $44 \%$ greatly exceeded the mean rise of $17 \%$. The characteristic feature of this group is the high lability index, some of the highest values being found in association with an F.E.V. at rest which is almost normal.

The resting F.E.V..$_{1}$ in group 3 is characteristically low, and the highest value after bronchodilatation with drug and exercise is, by definition, outside the predicted normal range. The lability index is variable, but usually lower than in group 2 subjects.

Sixteen subjects were examined on two occasions (Table III) At the second examination one subject was placed in group 1 , 10 in group 2, and five in group 3. The data from the first examination do not allow a comparison of lability, but it can be seen that the mean falls were comparable-33\% and $28 \%$ respectively at the first and second examinations. The general impression is that bronchial lability does not change markedly in individual asthmatics over periods of several years.

TABLE III.-Three-year Follow-up Study of 16 Children with Asthmo

\begin{tabular}{cc|c|c|c}
\hline Assessment & $\begin{array}{c}\text { Pred. N. } \\
\text { F.E.V.1 (1.) }\end{array}$ & $\begin{array}{c}\text { Mean F.E.V.1 } \\
\text { at Rest, \% N.* }\end{array}$ & $\begin{array}{c}\text { Lowest } \\
\text { F.E.V.1\% N.* }\end{array}$ \\
$\begin{array}{lll}\text { 1st (Nov. 1961-Oct. 1962) } \\
\text { 2nd (June 1964-May 1965) }\end{array}$ & $\cdots$ & $\begin{array}{l}2 \cdot 22(1 \cdot 36-3 \cdot 23) \\
2 \cdot 95(2 \cdot 16-3.8)\end{array}$ & $\begin{array}{c}76(34-97) \\
70(50-102)\end{array}$ & $\begin{array}{c}43(15-74) \\
42(16-81)\end{array}$ \\
\hline
\end{tabular}

- Percentage predicted normal F.E.V.1

\section{Clinical Features of Each Group}

Group 1.-Attacks are never severe, and usually are infrequent. There may be long periods without symptoms. Exercise tolerance is normal or only slightly impaired.

Group 2.-Attacks may be severe and frequent, but, on the other hand, there may be symptom-free intervals of several months between attacks. A cough, wheeziness, and dyspnoea often occur at night. Exercise tolerance may be greatly reduced owing to the occurrence of bronchoconstriction during exercise. However, many subjects in this group have an F.E.V., immediately after exercise equal to or above the resting value, indicating no bronchoconstriction during exercise, and these have a good exercise tolerance. Some subjects have a clear history of sensitivity to specific allergens.

Group 3.-This is the most severe form of asthma, with early onset and frequent, severe attacks. Between attacks subjects are seldom free from symptoms, and exercise tolerance is always impaired. Often there is associated respiratory infection of low grade. Intercurrent respiratory infection may produce a severe exacerbation of the disease. A history of sensitivity to specific allergens is less clear-cut.

\section{Repeatability}

Duplicate estimations of lability were made in 12 subjects (Table IV). It has been assumed that the coefficient of variation is the same at all levels of lability, which approximates to a constant standard deviation in the logarithms of the lability values. The coefficient of variation $=20 \%$.

TABLE IV.-Duplicated Estimations of Lability in 16 Subjects

\begin{tabular}{c|c|c|c|c|c}
\hline Subject & $\begin{array}{c}\text { Lability } \\
\text { Index }\end{array}$ & Subject & $\begin{array}{c}\text { Lability } \\
\text { Index }\end{array}$ & Subject & $\begin{array}{c}\text { Lability } \\
\text { Index }\end{array}$ \\
\hline 1 & 27,14 & 5 & 61,46 & 9 & 39,58 \\
2 & 52,57 & 6 & 86,92 & 10 & 43,41 \\
3 & 74,55 & 7 & 77,61 & 11 & 69,56 \\
4 & 76,70 & 8 & 46,42 & 12 & 40,51 \\
\hline
\end{tabular}




\section{Lung Volumes}

The total lung capacity (T.L.C.), residual capacity (R.C.), and $\frac{\text { R.C. }}{\text { T.L.C. }} \%$ in group 1 subjects are normal, with the exception of the R.C., which tends to be raised (Table V). These values are raised in groups 2 and 3 to the same degree with

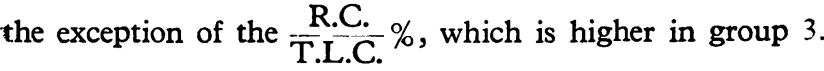

\begin{tabular}{c|c|c|c|c|c}
\multicolumn{8}{c}{ TABLE V.-Changes in Lung Volumes } \\
\hline \multirow{2}{*}{ Group } & $\begin{array}{c}\text { Pred. N. } \\
\text { F.E.V.1 }\end{array}$ & $\begin{array}{c}\text { F.E.V.1 at } \\
\text { Rest \% N.* }\end{array}$ & T.L.C. & R.C. & R.C./T.L.C. \\
\hline$\%$
\end{tabular}

* Percentage predicted normal F.E.V.1

\section{The Ratio F.E.V.1/F.V.C.}

Engström et al. (1959) have suggested that the ratio F.E.V.;/ F.V.C. is a truer expression of increased airways resistance in the asthmatic than the F.E.V. , $_{1}$ because it is less influenced by body size and other factors. The relation between this ratio and the classification described here is set out in Table VI. Group 2 is divided into low and high lability subgroups.

\begin{tabular}{|c|c|c|c|c|}
\hline \multirow[b]{2}{*}{$\begin{array}{l}\text { No. of subjects } \\
\text { Lability indoax } \\
\text { F.E.V./F.V.C. } \% \\
\text { at rest } \\
\text { F.E.V.1/F.V.C. \% } \\
\text { after maximum } \\
\text { bronchodilatation }\end{array}$} & \multirow{2}{*}{$\begin{array}{c}\text { Group 1 } \\
10 \\
<30 \\
82(69-89) \\
\left.1<70^{*}\right) \\
84(78-90)\end{array}$} & \multicolumn{2}{|c|}{ Group 2} & \multirow{2}{*}{$\begin{array}{c}\text { Group } 3 \\
10 \\
56(44-72) \\
8<70 \\
65(57-77) \\
8<70\end{array}$} \\
\hline & & $\begin{array}{c}10 \\
35-49 \\
65(54-85) \\
8<70 \\
77(67-87) \\
2<70\end{array}$ & $\begin{array}{c}10 \\
62-91 \\
67(46-86) \\
5<70 \\
80(64-94) \\
1<70\end{array}$ & \\
\hline
\end{tabular}

- Denotes number of subjects with F.E.V.1/F.V.C. \% less than 70

In nearly all Engström's normal subjects, the ratio F.E.V. $/$ F.V.C. exceeded $70 \%$. In 9 out of 10 group 1 subjects the ratio was normal and in 8 out of 10 group 3 subjects it was abnormal. The majority of group 2 subjects have an abnormal value, but after maximum bronchodilatation only two and one of them in each subgroup remained abnormal. Within group 2 there is no correlation between the lability index and the function F.E.V. ${ }_{1}$ F.V.C.

\section{Nitrogen Washout Studies}

The inequality of ventilation as measured by this test was normal in some group 2 subjects but high in others $(>2 \%)$

TABLE VII.-Increase of \% Nitrogen Over $500 \mathrm{ml}$. of Expired Gas in TABLE VII.-Increase of \% 10 Subjects

\begin{tabular}{c|c|c|c}
\hline Subject & $\begin{array}{c}\text { \% Pred. N. } \\
\text { F.E.V.1 }\end{array}$ & \% Nitrogen & Group \\
\hline 1 & 99 & $<3$ & 2 \\
2 & 83 & $<.5$ & 2 \\
3 & 74 & $2 \cdot 5$ & 2 \\
4 & 61 & 2.5 & 2 \\
5 & 55 & 3.5 & 3 \\
6 & 58 & 3.4 & 3 \\
7 & 52 & 3.4 & 3 \\
8 & 51 & 4.7 & 3 \\
9 & 50 & 4.8 & 3 \\
\hline 10 & 47 & &
\end{tabular}

TABLE VIII.-Increase in \% Nitrogen Over $500 \mathrm{ml}$. Expired Gas in One Subject from Each Group

\begin{tabular}{c|c|c|c|c}
\hline \multirow{2}{*}{ Group } & \multicolumn{2}{|c|}{ At Rest } & \multicolumn{2}{|c}{ After Exercise } \\
\cline { 2 - 5 } \cline { 3 - 4 } & F.E.V.1 \% N. & $\%$ Nitrogen & F.E.V.1 \% N. & $\%$ Nitrogen \\
\hline 1 & 104 & $<1.5$ & 97 & $<1.5$ \\
2 & 99 & 3.0 & 63 & 4.0 \\
3 & 47 & 4.8 & 25 & 7.0 \\
\hline
\end{tabular}

(Table VII). All group 3 subjects had abnormal values. Observations on the effect of exercise (eight minutes' running) are limited, but suggest that inequality increases after exercise in groups 2 and 3, but not in group 1 (Table VIII).

\section{Children with Hay-fever}

Table IX shows the results in 13 children seen at the clinic with hay-fever and no history of asthma. Two had an F.E.V. at rest of $73 \%$ and $77 \%$ predicted normal, but the remainder were within the normal range. Values for the lability index were abnormal in six subjects. Two of these fall into group 1 and the remainder into group 2 . All six must be regarded as potential asthmatics. This accords with the clinical experience that a proportion of children with hay-fever develop asthma later in childhood or adult life. Frankland and Gorrill (1953) reported that $43 \%$ of their patients did so, which is similar to the proportion with high lability observed here.

TABLE IX.-13 Children with Hay-fever

\begin{tabular}{|c|c|c|c|c|}
\hline \multirow{2}{*}{$\begin{array}{l}\text { Age in } \\
\text { Years }\end{array}$} & \multirow{2}{*}{$\begin{array}{c}\text { Pred. N. } \\
\text { F.E.V.1 } \\
\text { Litres }\end{array}$} & \multicolumn{2}{|c|}{ F.E.V. 1 at Rest } & \multirow{2}{*}{$\begin{array}{c}\text { Lability } \\
\text { Index } \\
(\%)\end{array}$} \\
\hline & & Litres & $\%$ N. & \\
\hline $\begin{array}{l}15 \\
13 \\
14 \\
14 \\
12 \\
15 \\
12 \\
11 \\
10 \\
12 \\
14 \\
13 \\
14\end{array}$ & $\begin{array}{l}3.95 \\
2 \cdot 15 \\
2 \cdot 30 \\
3.55 \\
2 \cdot 10 \\
2.90 \\
2 \cdot 45 \\
1 \cdot 75 \\
1.80 \\
2 \cdot 25 \\
2 \cdot 20 \\
2.90 \\
3.85\end{array}$ & $\begin{array}{l}3.87 \\
1.90 \\
1.85 \\
2.60 \\
1.74 \\
3.60 \\
1.89 \\
1.60 \\
1.62 \\
2.04 \\
1.95 \\
2.38 \\
3.38\end{array}$ & $\begin{array}{r}98 \\
88 \\
80 \\
73 \\
83 \\
124 \\
77 \\
91 \\
90 \\
91 \\
89 \\
82 \\
88\end{array}$ & $\begin{array}{r}16 \\
7 \\
8 \\
10 \\
15 \\
32 \\
19 \\
37 \\
33 \\
54 \\
9 \\
21 \\
15\end{array}$ \\
\hline
\end{tabular}

\section{Discussion}

The increase of airways resistance which is responsible for the low F.E.V., in asthmatics is clearly due, on histological evidence from those dying during an attack, to two factors: luminal obstruction and inflammatory thickening of the mucosa. But many asthmatics have an F.E.V..$_{1}$ at rest, after maximum bronchodilatation with drug and one minute's exercise, which is within the normal range, although not necessarily normal for them. In these subjects the factors of luminal obstruction and mucosal thickening must cause only minor encroachment on the airways, yet the lability index is highest in this group, suggesting the operation of a third factor. This is likely to be bronchiolar muscle contraction, which is primarily responsible for the lability as measured by the technique described. Against this it could be argued that the stimulus of exercise produces a degree of vascularity and outpouring of mucoid material which is responsible for the post-exercise fall of F.E.V..$_{1}$. If this were the case one would expect to find that the fall occurs during exercise. In some subjects it does, but in many with a marked post-exercise fall the level immediately after exercise is at or above the resting level (Jones et al., 1962). Moreover, the fall is often so short-lived that it is more in keeping with a readily reversible process such as muscle contraction than a vascular and exudative phenomenon. Presumably, allergens act on the mucosa to produce, on the one hand, release of substances which result in múcosal thickening and exudation, and, on the other, an increased tendency to bronchiolar muscle contraction. But to operate the latter mechanism some triggering stimulus is required such as physical exercise and perhaps psychological factors.

Subjects in groups 1 and 2 have minimal persistent luminal obstruction, and the division between these groups is purely in terms of the degree of lability of the bronchi, which is reasonable because this correlates well with the severity and frequency of attacks. Group 3 subjects tend to have a lower lability index than group 2 subjects, but this is not evidence that the muscular factor is less active in this group. It is obscured by the more 
severe degree of mucosal thickening and luminal obstruction that is present. This point is illustrated by observing the effect of prednisolone in a group 3 subject. A boy of 10 years had an F.E.V., at rest of 1.2 litres. He was put on prednisolone $20 \mathrm{mg}$. daily for four days, after which the resting value had risen to 2 litres. The lability index before the steroid was $56 \%$, but after reduction of the mucosal inflammation, as indicated by the rise in the resting F.E.V..$_{1}$, the lability went up to $69 \%$. Steroids do not appear to diminish the lability index, and values between 40 and $60 \%$ have been repeatedly observed in subjects on steroids.

Symptomatology and the course of the disease in group 3 subjects is dominated by the mucosal factor, which produces a fixed increase in airways resistance. In groups 1 and 2 the muscular factor dominates and bronchial lability, measured by the lability index, determines the severity of symptoms.

Although the results are interpreted here in terms of a mechanism involving mucosal and neuromuscular factors, this view must be regarded as tentative until more evidence becomes available. It is an interpretation, however, which offers a rational explanation for otherwise puzzling clinical and physiological features of asthma.

\section{Course of the Disease}

Improvement could theoretically be due to a diminished sensitivity to allergens with resolution of the mucosal disease. Although in general asthmatics tend to remain remarkably stable and within their own group, regression from group 3 to 2 or from 2 to 1 has occasionally been observed. However, a reduction in the degree of mucosal disease does not appear to be the usual reason for improvement. For example, when a group 2 subject has been free from attacks for months, it might be expected that this would be associated with a reduction in his lability index to within the normal range, but this has never been observed. The lability index usually remains abnormal despite the diminished frequency or severity of attacks, which suggests that triggering factors are important for the production of symptoms. Therefore, although symptoms due to bronchoconstriction cannot occur without abnormal lability, they may not occur when it is present, so that the criterion of " cure" or recovery must include a normal lability index.

\section{Infection}

Infection operates in a non-specific way by narrowing the bronchi without influencing lability, and, as expected, its effect is greatest in group 3, where there is already appreciable narrowing of the airways. Bacteria may also increase mucosal disease by acting as allergens and hence increase lability, but so far there is no evidence on this point.

\section{Exercise Tolerance}

Exercise tolerance is markedly impaired in group 3 subjects owing to the fixed increase in airways resistance. In group 2 subjects exercise tolerance is variable, depending upon the degree of bronchoconstriction which develops during exercise. In some subjects bronchoconstriction does not occur during exercise but begins one to two minutes afterwards, so that they have a good exercise tolerance. In others it occurs during exercise, causing an impaired exercise tolerance. Group 1 subjects usually have a good exercise tolerance, because bronchoconstriction is limited in degree and usually occurs only after exercise.

\section{Classification}

Classifications of asthma which are based upon supposed aetiological or precipitating factors such as allergy, infection, and emotion (Rackemann, 1947 ; Williams et al., 1958) are valuable, but there is no evidence to suggest that they produce physiologically distinct types of asthma. A classification based upon severity of symptoms, such as that of Pearson (1958), is similarly of clinical value, but cannot be related closely to the physiological abnormalities. In an attempt to offer an objective assessment of ventilatory impairment, Pearson (1963) described a classification based upon the use of the peak-flow meter. Three groups are defined in terms of the degree of reduction in peak expiratory flow rate, which he relates to the symptomatology. The F.E.V., may be used in a similar fashion. Engström et al. (1959) advocated the use of the function F.E.V. ${ }_{1}$ F.V.C., because it is less dependent upon body size and avoids the use of predicted normal values. For these reasons a better correlation is claimed with disability. These classifications are not entirely satisfactory, because the degree of airways obstruction is determined by two factors in proportions which vary with time: a relatively fixed component due to mucosal thickening and luminal obstruction, and a labile component. Moreover, the latter may be minimal at the time of measurement, yet be responsible for severe symptoms. Therefore a single measurement may be misleading, and in order to correlate symptomatology with the physiological abnormalities it is necessary to separate these components and express each objectively. The classification offered here endeavours to do this.

\section{Summary}

Evidence is produced to show that a single estimation of the F.E.V. ${ }_{1}$ test at rest is of limited value in asthma. A technique is described which provides the information necessary for a diagnosis and proper assessment of the disease. A classification based upon this technique is described.

Asthmatics with an F.E.V., below the predicted normal range after maximum bronchodilatation with isoprenaline aerosol and one minute's exercise are thought to have an increase of airways resistance due primarily to mucosal thickening and airways obstruction, and are separated off as group 3. The remainder are divided into two groups according to the degree of lability of the bronchi-that is, the tendency to dilate and constrict in response to appropriate stimuli. This measurement is called the lability index.

\section{Classification}

Group 1: F.E.V..$_{1}$ at rest, after maximum bronchodilatation with drugs and one minute's exercise, within predicted normal range. Lability index 15 to $30 \%$.

Group 2: F.E.V., at rest after maximum bronchodilatation with drug and one minute's exercise, within predicted normal range. Lability index $>30 \%$.

Group 3: F.E.V.$_{1}$ at rest, after maximum bronchodilatation with drug and one minute's exercise, below predicted normal range. Lability index variable.

I wish to thank the paediatricians of Alder Hey Children's Hospital, who made this work possible by kindly allowing me to examine patients under their care; $\mathrm{Mr}$. K. Tweedie, of the subdepartment of mathematical statistics, University of Liverpool, for carrying out the statistical calculations; and Mr. J. C. Kay for technical assistance.

\section{REPERENCES}

Engström, I., Escardó, F. E., Karlberg, P., and Kræpelien, S. (1959). Acta paediat. (Uppsala), 48, 114.

Frankland, A. W., and Gorrill, R. H. (1953). Brit. med. F., 1, 761.

Gaensler, E. A. (1951). Amer. Rev. Tuberc., 64, 256

Gilson, J. C., and Hugh-Jones, P. (1949). Clin. Sci., 7, 185

Jones, R. S., Buston, M. H.; and Wharton, M. J. (1962). Brit. F. Dis. Chest, 56, 78 .

Wharton, M. J., and Buston, M. H. (1963). Arch. Dis. Childh., 38,539 .

McKerrow, C. B., McDermott, M., and Gilson, J. C. (1960). Lancet, $1,149$.

Pearson, R. S. B. (1958). Acta allerg. (Kbh.), 12, 277.

(19636). Folia allerg. (Roma), 10, 421.

Rackemann, F. M. (1947). Amer. Y. Med., 3, 601.

Williams, D. A., Lewis-Faning, E., Rees, L., Jacobs, J., and Thoma, A. (1958). Acta allerg. $(\mathrm{Kbh}), 12,376$.

Wright, B. M. (1958). Lancet, $2,24$. 